\title{
PLANNER'S APPRAISAL OF THE INDICATORS OF DOMESTIC WATER STRESS IN HONG LOCAL GOVERNMENT AREA OF ADAMAWA STATE, NIGERIA
}

\author{
PHANUEL B. JOSHUA ${ }^{1}$, ABAYOMI P. AJAYI ${ }^{2}$, FELIX A. ILESANMI ${ }^{3}$ \\ \& MOHAMMED A. HUSAIN ${ }^{4}$ \\ ${ }^{1}$ Department of Urban and Regional Planning, University of Maiduguri, PMB 1069, Maiduguri, Borno State \\ ${ }^{2,3,4}$ Department of Urban and Regional Planning, Modibbo Adama University, PMB 2076, Yola, Adamawa State
}

\section{ABSTRACT}

This paper examined and appraised the indicators of Domestic Water Stress (DWS) which is a ratio between water requirement and water availability per capita per day or per household per day. The appraisal is done in line with the planner's point of view. Domestic Water Stress Index (DWSI) was developed from the United Nations minimum standards of 50 litres per capita per day with a range between 0.1 to 1+ with categories of stress classified severe stress, partial stress and no stress. A total of 2,135 households were sampled randomly where one respondent was chosen also randomly. Correlation analysis was used to examine the relationship between the DWS, Local Water Stress (LWS) and Perceived Water Stress (PWS) and their associated indicators such as distance to sources, queuing time, degree of flow, total time spent on accessing water, seasonal changes and number of existing water supply infrastructure. Results indicated that there is a correlation between DWS and these indicators. With this scenario, the planner makes appraisal of the incidence of DWS in relation to these indicators in a manner that balances their implications on the quantity of water to households or individuals. Planner's role in appraising water related problems such as domestic water stress cannot be overemphasized because of its sustainable outcomes. It is recommended that a sustainable plan of water supply can be prepared using this appraisal.

KEYWORDS: Appraisal, Domestic Water Stress, Indicators, Planning, Water Supply \& Planner

Received: Jul 01, 2021; Accepted: Jul 21, 2021; Published: Aug 17, 2021; Paper Id.: IJEEFUSDEC202110

\section{INTRODUCTION}

Planners view water stress as a situation which occurs when the functions of water in the system do not reach the standards of policies and perceptions of the population in an appropriate quantity and quality at an appropriate scale (Aquastress, 2008, Joshua, 2018). The system should ensure a balanced water supply and demand in the area of interest. However, the mitigation plan needs to be able to adapt to the specific situation a society may face at a particular time. According to Larson (undated), planners acknowledge that there is indeed water stress, but they are more concerned about indoor water use and inadequate access to water as indicators of water stress. Beyond climate, growth and outdoor water use are seen as critical stressors among land use planners as against the concerns of water managers who are worried about natural water variability. Some indicators have been combined as measures of various dimensions of water stress, including the widely used indicators relating the quantity of water available to the amount needed for certain activities (Aquastress, 2008). Global Urban Research Unit (GURU) of the School of Architecture, Planning and Landscape, University of Newcastle stated that 'Water stress' is meant to denote any short-fall in the provision of potable water supply existing after viable economic and environmental limits to water extraction and distribution have been reached. The Royal Town Planning Institute (RTPI. 2014) 
observed that the household growth and population increase will increase water demand by 5\% in the UK by the year 2020; therefore, proactive planning is required to deal with the issues of water stress.

\section{Aim and Objectives}

The aim of this paper is to appraise Domestic Water Stress (DWS) from the perspective of a planner with a view to proposing a sustainable water supply strategy to mitigate the problem. This can be achieved through the following objectives:

- To examine DWS from a planners' perspective

- To describe the planning standards for rural and urban water supply scheme

- To develop an index that will show the level of DWS in the Study Area

- To show the indicators of DWS in the Study Area

- To establish the relationship between the indicators and DWS in the Study Area

\section{Study Area}

Hong is one of the 21 Local Government Areas (LGAs) of Adamawa State created in 1987 during the defunct Gongola State. It has its headquarters in Hong town being the largest settlement in the LGA and is classified by Ilesanmi (1999) as a third order core urban settlement in Adamawa state. Hong LGA is located between latitudes $10^{\circ} 00^{\prime} 00^{\prime \prime} \mathrm{N}$ and $10^{\circ} 35^{\prime} 00^{\prime}$ 'N and longitudes $12^{\circ} 35^{\prime} 00^{\prime \prime} \mathrm{E}$ and $13^{\circ} 20^{\prime} 00^{\prime}$ 'E. It has a total land area of 2,419.11 km² (Bashir and Raji, 1999). Hong LGA consists of seven (7) districts namely; Hong, Dugwaba, Pella, Kulinyi, Hildi, Gaya and Uba districts. Each of the districts has a District head at the district headquarters in Hong, Pella, Kala'a, Uba, Hildi, Garaha and Kuva Gaya. According to the Compendium of localities compiled by the National Population Commission in 2014, Hong Local Government Area has a total of 220 autonomous communities. Figure 1 shows Nigeria with specific reference to Adamawa State while Figure 2 depicts Hong LGA (Study Area) within Adamawa State.

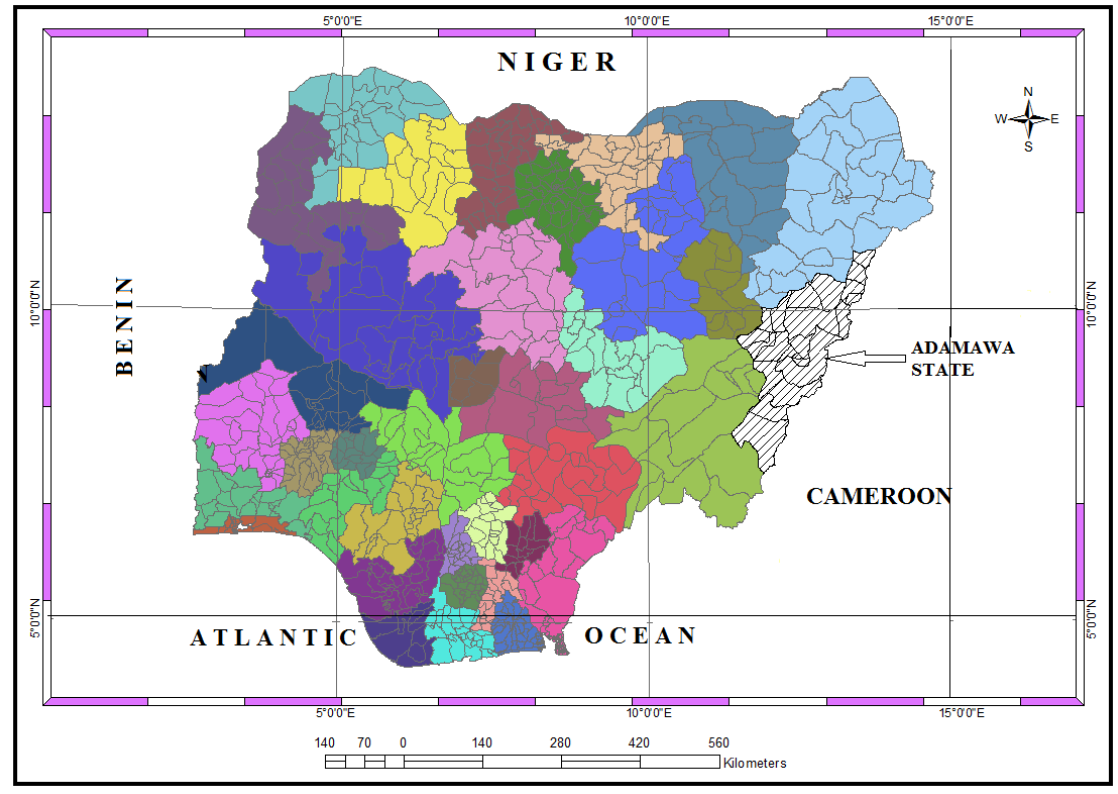

Figure 1: Nigeria Showing Adamawa State.

Source: Joshua, 2018 


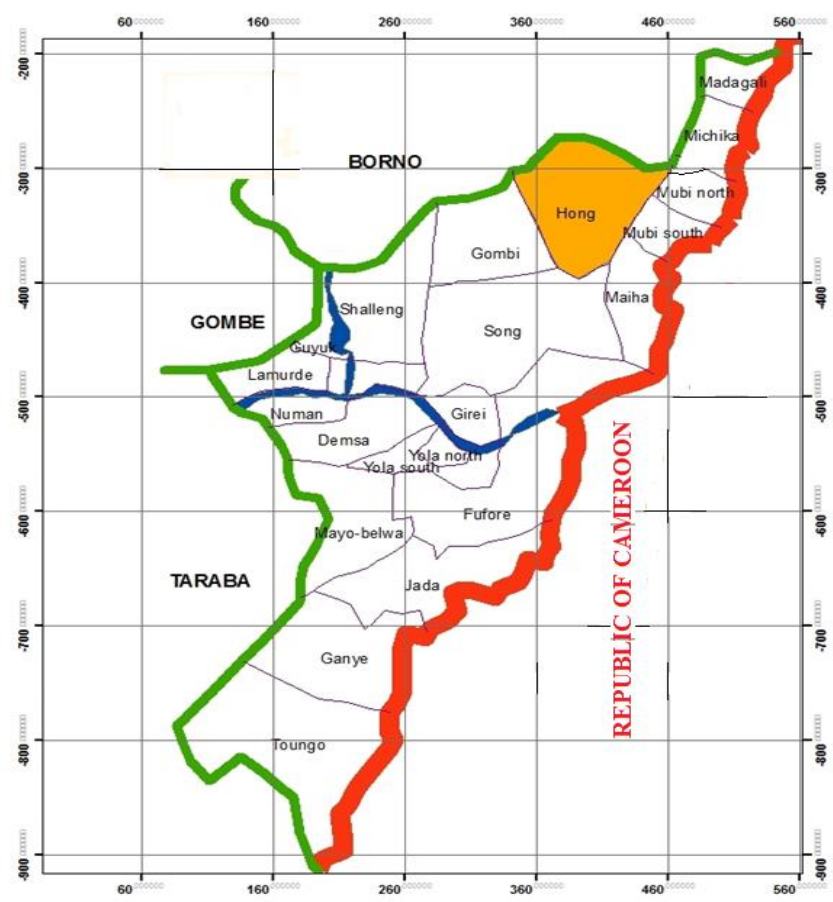

Figure 2: Adamawa State showing Hong LGA (Study Area).

Source: Joshua, 2018

\section{LITERATURE REVIEW}

Faniran (1992) and Abdul (1997) in Ishakuet al., (2010) noted water stress (scarcity) is due to inadequate knowledge about available water resources at all levels of planning and climate changes. Planning approaches to mitigating water stress put the water managers responsible for protecting the societies from the negative consequences of insufficient water supply. It is against this backdrop that Joshua et al. (2019) suggested that water stress at the domestic level requires the expertise of a planner to mitigate through rainwater harvesting technique through design and installation of the facilities after estimates are done.Since a water system's success is measured by its ability to ensure regular supply, and shielding the end users from irregular supply, a mitigation plan is devised in order to safeguard supply. The European Union (EU) (2014) gave a planning process as a water framework directive which involves different stages of activities required. The planning stage is the first activity which will lead to public consultation (participatory planning) before the plan is adopted. When the plan has been adopted, enforcement is carried out while risk analysis is also done as a form of evaluation; if there is any problem encountered, it reverts to the planning stage again. In all these various stages, monitoring and reporting is required. Details are presented in figure 1. 


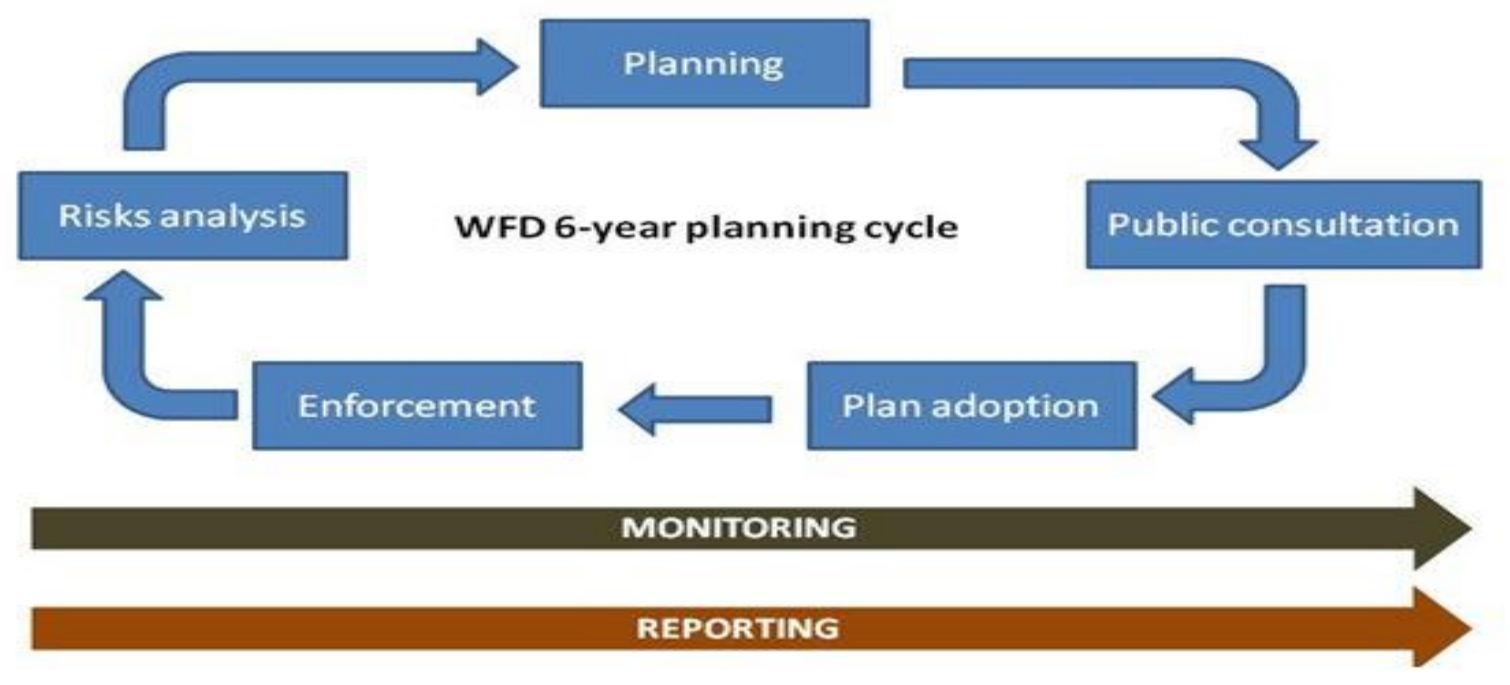

Figure 3: Planning Process for EU Water Framework Directive.

Source: Adapted from EU, 2014

(http//fdehemptinne.files.wordpress.com/2011/01/planning-2222-jpg) by Joshua, 2018

The planner is also concerned about the comfort of residents in water usage example queuing time, length of queue, distance from home and cost of meeting family or institutional water need and indeed the quality/safety of water available. The planner sees stress in inability to achieve the desired environmental quality due to water shortage or cost. The planner also sees stress in continuous use of facilities like the generator and water pump if it cannot assist in giving periodic rest for the supply infrastructure. This is evident in the work of Chiori (2018) work assessed the challenges of water supply in Lagos and tied the current water supply crisis (water stress) to poor operational efficiency of water treatment facilities, low-cost recovery, increasing population size and poor governance in the Lagos water corporation. The task is then on the planner to ensure sustainable water supply to the end users in urban and rural dwellers (Joshua et al., 2019).

\section{Planning Standards for Urban and Rural Water Supply}

Water supply is a right of both rural and urban dwellers; this is part of the national development plans. Water is essential for sustenance of life and determines the overall socio-economic development of any nation (Nwankwoala, 2011). The UN proposed a basic water requirement of 50 litres per capita per day while other agencies and partners of the UN are of the view that a minimum of 20 litres per capita per day is adequate for a healthy human lifestyle especially in rural areas of developing countries. However, urban access- reported as 94\% in developing regions- is often seriously deficient. Townspeople may be assessed as "fully covered" when taps or standpipes are installed every 200 metres and users are obliged to share with 5,000 others. Village taps or pumps at similar distances serve far fewer people and are far less likely to break down (Black and King, 2009). Sphere Project (2004) in her Charter Handbook also gives maximum number of people per water source and queuing time as 250 people per tap and basic flow rate (yield) of 7.5 litres per minute; 500 people per hand-pump based on a flow rate of 16.6 litres per minute and 400 people per single-user open well based on a flow rate of 12.5 litres/minute. The Charter handbook has the following minimum standards for water supply and sanitation:

- The maximum distance from any household to the nearest water point is 500 metres. 
- Queuing time at a water source is no more than 15 minutes.

- It takes no more than three (3) minutes to fill a 20-litre container.

Water sources and systems are maintained such that appropriate quantities of water are available consistently or on a regular basis. Furthermore, rapid urbanization means that water supply provision is not keeping pace with population growth in towns and cities. The Nigerian Water supply sanitation Policy [NWSSP] (2000) document states a standard for water supply, service population and service radius for Urban, Semi-urban and Rural dwellers. Separate water supply and sanitation considerations are made to match the three socio-economic profiles of the population as follows:

- Rural water supply guaranteed minimum level of service 30 litres per capita per day within 250 metres of the community of 150 to 5,000 people, serving about $250-500$ persons per water point.

- Semi-urban (small towns) water supply represents settlements with a population of between 5,000-20,000 with a fair measure of social infrastructure and some level of economic activity with a minimum supply standard of 60 litres per capita per day with reticulation and limited or full house connections as determined by the beneficiaries / Government.

- Urban water supply of 120 litres per capita per day for urban areas with a population greater than 20,000 inhabitants to be served by full reticulation and consumer premises connection.

It is on basis of these existing standards that the paper draws inferences from a planner's point of view of the indicators of domestic water stress and their implication on the water availability and access in Hong LGA.

\section{MATERIALS AND METHODS}

The study will utilize the existing planning standards as a benchmark for the appraisal of the situation of DWS and its indicators in Hong LGA of Adamawa State. A total of 2,135 households were sampled out of the estimated42, 729 households (HHs) (NPC, 2010, Joshua, 2017, 2018) to assess their level of access to water supply and adequacy using the UN and the Nigerian benchmarks for rural, semi-urban and urban areas.

Similarly, the study employed the use of both qualitative and quantitative (statistical) techniques in the analysis of data collected for the research. Descriptive statistics such as cross tabulation, Tables, percentages, diagrams, graphs, and charts were utilized to present the results clearly. The levels of domestic water stress are assessed through the level of access to water by members of households per capita per day. Domestic water stress index (DWSI) was calculated using the UN minimum standard (50 litres/capita/day) where a ratio of quantity of water available against quantity of water requirement is obtained to show the level of stress in 2,135 house holdsrandomly chosen in Hong local government area (LGA) of Adamawa State, Nigeria. Local Water Stress (LWS) is calculated using National water supply and sanitation policy standard of 30 litres/capita/day whereas Perceived Water Stress (PWS) is calculated using the perception of the people on how much water they need as against what is available to them. The ratio of the DWS, LWS and PWS is obtained through the constructed formula (Ahluwalia, 2008, Joshua, 2017, 2018, Joshua et al., 2020) as follows:

Domestic Water Stress Index (DWSI)

$$
\mathrm{DWSI}=\frac{\mathrm{QWA}_{\mathrm{c}}}{\mathrm{QWR}_{\mathrm{c}}}
$$




$$
=\frac{\sum \mathrm{QWA}_{\mathrm{h}}}{\sum \mathrm{QWR}_{\mathrm{h}}}
$$

Where:

$\mathrm{QWA}_{\mathrm{c}}$ is quantity of water available per capita $\mathrm{c}$

QWR cis quantity of water required per capita $\mathbf{c}$.

$\sum \mathrm{QWA}_{\mathrm{h}}$ is the summation of quantity of water available per household $\mathrm{h}$

and, $\sum \mathrm{QWR}_{\mathrm{h}}$ is the summation of quantity of water required per household $\mathrm{h}$

Ratios 0.1-0.49 signify severe water-stress; 0.5-0.99 is partial water-stressed, $1+$ indicates no stress.

Correlation analysis was employed in the data analysis to establishes statistical relationship between domestic water stress (DWS), local water stress (LWS) and perceived water stress (PWS) and a set of other indicators/variables as follows:

- $\quad$ Number of existing water supply infrastructure (INFA)

- $\quad$ Discharge adequacy (DA)

- $\quad$ Queuing time $(\mathrm{Qt})$

- Distance to water sources (Ds)

- Seasonal changes

\section{RESULTS AND DISCUSSIONS}

Residents of Hong LGA usually source water from rivers/streams, ponds, wells, rainfall, earth dams and boreholes for different uses. However, most communities across the LGA depend on water from wells and boreholes for domestic uses. For many communities also, the question of quality does not count as the conventional portable water sources (boreholes, wells, standpipes and taps) are absent thereby leaving them with no choice but to use any available water they can find. Research revealed that communities along the existing rivers dig shallow wells during dry season to access water for domestic uses.

There are several factors that have influence on domestic water stress in the study area such as distance to water sources, queuing time at water sources, total time spent on accessing water daily, perceived discharge rate and seasonal changes. On the distance to water sources, majority (62.5\%) of the respondents travel or walk for a distance of 250 metres and above to access water while $37.4 \%$ only walk for less than 250 metres to obtain water. However, this is not applicable to $0.1 \%$. This means that most people in the study area move long distances to access water and this scenario tends to affect how much water is available to households or individuals on a daily basis. Similarly, people spend a long time queuing up for water at the source as it is indicated by $79.7 \%$ of the respondents who spend 15 minutes and above to queue up or to access water at the boreholes or wells which are common in the study area. Only $19.9 \%$ of the respondents said they spend less than 15 minutes at water source queuing up or accessing water. 
The cumulative time spent on fetching water daily influences how much water households or individuals can have daily. In Hong LGA, a greater number of households spend substantial time on accessing water daily. This study revealed that $81.5 \%$ of the respondents spend 1 hour and above daily to fetch water for domestic uses while only $18.3 \%$ spend less than 1 hour to fetch water for their household needs daily as described in Table 1. An inference is provided after comparison with the UN standards for some of the indicators such as distance, queuing time and discharge rate at source.

Suffice to say that time generally plays a significant role in determining the quantity of water per capita per day and consequently water stress. The longer the time (queuing time inclusive) spent on accessing water, the less the quantity of water that can be available for households or individuals. The Sphere Project proposes a queuing time of not more than 15 minutes at source per user.

Discharge/flow adequacy at water sources described by respondents show that $78.9 \%$ said discharge/flow is not adequate while $20.8 \%$ agreed that there is adequate discharge/flow at water source(s) in the study area. There is the question of seasonal changes in discharge/flow of water at source which $16.2 \%$ agreed that discharge/flow of water at source is affected by seasonal changes while $83.6 \%$ said the discharge/flow at sources is not affected by seasonal changes. The responses of the sample households are captured in Table 1.

Table 1: Indicators of Domestic Water Stress

\begin{tabular}{|l|c|c|l|l|}
\hline \multicolumn{1}{|c|}{ Distance to Water Sources } & Freq. & Per cent (\%) & UN Standards & Inference \\
\hline$<250$ metres & 798 & 37.4 & 250 metre & Majority \\
\hline 250 metre and above & 1,335 & 62.5 & & Walk longer \\
\hline Not applicable & 02 & 0.1 & & Distance \\
\hline Total & 2,135 & 100 & & \\
\hline Queuing Time & & & Max.15 mins & Majority \\
\hline$<15$ minutes & 424 & 19.9 & & Queue for \\
\hline 15 minutes and above & 1,702 & 79.7 & & Longer time \\
\hline Not applicable & 09 & 0.4 & & \\
\hline Total & 2,135 & 100 & & \\
\hline Time spent on accessing waterdaily & & & Not available* & NA* \\
\hline$<1$ hour & 390 & 18.3 & & \\
\hline 1 hour and above & 1,739 & 81.5 & & \\
\hline Not applicable & 06 & 0.3 & & \\
\hline Total & 2,135 & 100 & & \\
\hline Discharge adequacy & & & 7.5 litres/min & Poor \\
\hline Yes & 445 & 20.8 & & discharge \\
\hline No & 1,684 & 78.9 & & For the \\
\hline Not applicable & 06 & 0.3 & & Majority \\
\hline Total & 2,135 & 100 & & \\
\hline Seasonal changes in discharge & & & Not available* & NA* \\
\hline Yes & 345 & 16.2 & & \\
\hline No & 1,784 & 83.6 & & \\
\hline Not applicable & 06 & 0.3 & & \\
\hline & $\mathbf{2 , 1 3 5}$ & $\mathbf{1 0 0}$ & & \\
\hline \multicolumn{1}{|c|}{ Total } & & & \\
\hline
\end{tabular}

Similarly, DWS, LWS and PWS were correlated with the indicators of water stress in the area to establish their relationships and their implications for a planner. Results revealed that there is a strong correlation between domestic water stress (DWS) and queuing time, flow rate, seasonal changes, and the time spent on fetching water as the correlation coefficients $r=-0.83$ (queuing time), -0.69 (flow rate), 0.91 (seasonal changes) and -0.81 for time spent on accessing water. However, there is no significant correlation between DWS and water supply infrastructure. Similarly, there is more 
correlation between PWS and all the indicators except water supply infrastructure. There is negative correlation between DWS and queuing time, distance to sources of water and total time spent on fetching water daily. This indicates that as the distance, queuing time, and time spent on fetching water reduces there is a corresponding increase in the values of DWS (quantity of water available). This also means that distance, queuing for water and time generally influence the quantity of water available per capita per day or per household. This situation is similar to what obtains in India as described by Haseena and Ajims (2014) that in many rural areas, women still have to walk a distance of about 2.5 kilometres to reach up to the source of water carrying heavy pots and still have to do other household chores afterwards. The planner, therefore, needs to provide a sustainable water supply plan that eliminates the negativities (shorten distance and reduce time) as proposed by Joshua et al. (2019) of these indicators so as to increase access to water for the households in the area (Hong LGA) through rainwater harvesting technique and planning. The correlation results are presented in Table 2.

Table 2: Correlation between Types of Domestic Water Stress and Some Indicators in the Study Area at p $<0.05$ Significance level

\begin{tabular}{|l|l|c|c|c|c|c|c|}
\hline Elements & Statistics & Distance & $\begin{array}{c}\text { Queuing } \\
\text { Time }\end{array}$ & $\begin{array}{c}\text { Degree of } \\
\text { Flow }\end{array}$ & $\begin{array}{c}\text { Season } \\
\text { Changes }\end{array}$ & $\begin{array}{c}\text { Total } \\
\text { Time }\end{array}$ & $\begin{array}{c}\text { No. of Water } \\
\text { Infras. }\end{array}$ \\
\hline DWS & $\begin{array}{l}\text { Cor. } \\
\text { Coefficient }\end{array}$ & -0.38 & -0.83 & -0.69 & 0.91 & -0.81 & 0.20 \\
\hline & $p$-value & .080 & .000 & .001 & .000 & .000 & .359 \\
\hline \multirow{2}{*}{ LWS } & $N$ & 2,135 & 2,135 & 2,135 & 2,135 & 2,135 & 2,135 \\
\hline & $\begin{array}{l}\text { Cor. } \\
\text { Coefficient }\end{array}$ & -0.14 & -0.71 & -0.55 & 0.56 & -0.29 & -0.35 \\
\hline & $p$-value & .510 & .001 & .012 & .009 & .185 & .111 \\
\hline \multirow{2}{*}{ PWS } & $N$ & 2,135 & 2,135 & 2,135 & 2,135 & 2,135 & 2,135 \\
\hline & $\begin{array}{l}\text { Cor. } \\
\text { Coefficient }\end{array}$ & -0.78 & -0.176 & -0.136 & 0.133 & -0.121 & 0.35 \\
\hline & $p$-value & .000 & .000 & .000 & .000 & .000 & .110 \\
\hline & $N$ & 2,135 & 2,135 & 2,135 & 2,135 & 2,135 & 2,135 \\
\hline
\end{tabular}

The implication of these correlations is that there is the need to make available water within easy reach of the people to reduce distance, queuing time and total time wasted on fetching water so as to enhance the quantity required to meet the stipulated minimum standard per capita per day in Hong LGA. These indicators are studied by the planner with a view to harmonising them for the conveniences of the end users of water in both rural and urban areas through sustainable planning. If water is provided within easy reach of the users, the quantity that will be available per capita will increase thereby reducing the queuing time and overall time spent on fetching water. These indicators are of the essence to the planner to draw up a sustainable plan to address domestic water stress in the area.

\section{CONCLUSIONS}

The planners' appraisal of DWS in Hong LGA has reflected in the results of the research which has shown that indicators such as distance to water sources, queuing time, degree of flow and seasonal changes influence the quantity of water available per capita per day showing the level of DWS in Hong LGA. The correlation between DWS and PWS with the indicators is also significant and so this gives the planner the basis for preparing a sustainable water supply plan to tackle water stress in the area.

\section{ACKNOWLEDGEMENT}

We acknowledge all the literary materials used for this paper and they have duly been referenced in the appropriate section. 


\section{REFERENCES}

1. Abdul, Y. (1997). Water Shortages in Damaturu: The way Forward for Solving Water Crisis in Desert Areas of Nigeria, Unpublished Essay.

2. Ahluwalia, P. (2008). Comprehensive Water Stress Indicators, TATA Consulting Engineers Limited, India, 19 p.

3. AQUASTRESS Project. (2008). Guidance on Water Stress Mitigation: Experiences and inspirations from AquaStress Project, European Commission collaborated Document, 128p.

4. Bashir, A. \&Raji, M.M. (1999). "Rural Settlements" In Adebayo, A.A. \&Tukur, A.L. (eds), Adamawa State in Maps, $1^{\text {st }}$ ed., Yola: Paraclete Publishers.

5. Black, M. \& King, J. (2009). The Atlas of Water: Mapping the World's Most Critical Resource, $2^{\text {nd }}$ edition, Los Angeles: University of California Press, 128 p.

6. Chiori, A. (2018). Urban Water Planning in Lagos, Nigeria: An Analysis of Current Infrastructure Developments and Future Water Management Solutions, Public Health Capstone Projects, School of Public Health, Georgia State University,57p.

7. European Union (EU) (2014). The Water Stress: Taking stock on Water Issues in the European Union. Faniran, A. (1992). Strategies for Water Supply Design in Developing Countries: An Appropriate Technology, Benin: University Press.

8. Global Urban Research Unit (nd). Planning for Water: Space, Time and the Social Organisation of Natural Resources, Electronic Working Paper No. 22, University of Newcastle, UK, 48p.

9. Ilesanmi, F.A. (1999). “Urban Settlements” In Adebayo, A.A. \&Tukur, A.L. (eds), Adamawa State in Maps, $1^{\text {st }}$ ed., Yola: Paraclete Publishers.

10. Ishaku, H.T., Husain, M.A., Dama, F.M., Zemba, A.A. \& Peters, A.A. (2010). Planning for Sustainable Water Supply through Partnership Approach in Wukari Town, Taraba State of Nigeria, Journal of Water Resources and Protection, Vol. 2, 916-922.

11. Joshua, P.B., Ibrahim, S., Glanda, G.G. \&Mayomi, I. (2020). Spatial Analysis of Domestic Water Stress for Effective Water Supply Planning in Hong Local Government Area of Adamawa State, Nigeria, Kaduna Journal of Geography, 2(2), Department of Geography, Kaduna State University, 18-35.

12. Joshua, P.B., Ilesanmi, F.A. \&Mshelizah, D.S. (2019). Planning for a Sustainable Water Supply through Improved Rainwater Harvesting System in Hong Local Government Area of Adamawa State, Nigeria, Global Journal of Earth and Environmental Science, 4 (5), 67-78.

13. Joshua, P.B. (2018). Effects of Domestic Water Stress on Socio-economic Indicators in Hong Local Government Area of Adamawa State, Nigeria, An unpublished PhD Thesis in the Department of Urban and Regional Planning, ModibboAdama University of Technology, Yola, 229p.

14. Joshua, P.B., Ilesanmi, F.A. \&Ajayi, A.P. (2017). An Assessment of the Effects of Domestic Water Stress on Income and Occupation in Hong Local Government Area of Adamawa State, Nigeria, FUTY Journal of the Environment, 11 (1), 91-100.

15. Larson. K. (nd). Views and Activities among Municipal Water Managers and Land Planners: Stressors and Strategies for Resource Management in Metropolitan Phoenix, Arizona, Global Institute of Sustainability, Arizona State University (ASU), $U S A, 5 p$.

16. National Water Supply and Sanitation Policy. (2000). Federal Ministry of Water Resources, Department of Water Supply and Quality Control, Abuja, Nigeria, First edition, 37p. 
17. National Population Commission. (2010). Population Distribution by Sex and Class-Size of Households (State and Local Government Area) Table HH-ADD1, 2006 Population and Housing Census Priority Table, Vol. IX, 14-25.

18. Nwankwoala, H.O. (2011). Localising the Strategy for Achieving Rural Water Supply and Sanitation in Nigeria, African Journal of Environmental Science and Technology, Vol.5, No.13.

19. Royal Town Planning Institute (RTPI) (2014). “Water” in Thinking Spatially: Why Places Need to be at the Heart of PolicyMaking in the Twenty First Century, Planning Horizons, No.1, 20-21.

20. Sphere Project (2004). Humanitarian Charter Handbook on Minimum Standards in Disaster Response, Steering Committee for Humanitarian Response (SCHR), Geneva, Switzerland,63-66.

21. Krishnamoorthy, C., K. Soorianathasundaram, and S. Mekala. "Effect of fertigation on FUE, quality and economics of cultivation in turmeric (Curcuma longa L.) cv. BSR 2." International Journal of Agricultural Science and Research (IJASR) 5.1: 67-72.

22. Gangawane, Prashant, and Usha Sayed. "Innovative Use of outdated Doxycycline Hydrochloride to Dye wool." International Journal of Medicine and Pharmaceutical Sciences; 4 (2): 4346.

23. Wahid, Nusrat, Mahtab Hussain Siddiqui, and Asma Siddiqua. "The Quality of affordable rental accommodation: a case study on female migrant RMG workers in Gazipur, Dhaka, Bangladesh." International Journal of Humanities and Social Science, IASET 9.2: 89-100.

24. Ketaren, S., et al. "Environmental health aspect in health emergency management (a case study: Sinabung Vulcanous Eruption)." Int. J. Appl. Nat. Sci 5: 47-56. 